\title{
O E-JUDICIÁRIO NO BRASIL: UMA BIBLIOMETRIA TEMÁTICA
}

AIRES JOSÉ ROVER

Doutor em Direito e professor do PPGD (Programa de Pós-Graduação em Direito - UFSC) e do PPGEGC, aires.rover@gmail.com

\section{Resumo}

Um novo modelo de Poder Judiciário está em construção e muitos são os temas que exigem reflexão. Observa-se que muitas publicaçóes têm sido realizadas nesse sentido, porém não há um trabalho sistemático de mapeamento desta situação, em revistas de alta qualificação. Nesse sentido, o objetivo deste trabalho é fazer um levantamento dos artigos indexados na base do SCIELO.br que respondam às três áreas temáticas: gestão do judiciário, Processo Eletrônico e segurança da informação no judiciário. Os resultados encontrados serão organizados em um esquema explicativo de subtemas. Para tanto o método de abordagem utilizado foi o indutivo com procedimento de estudo de caso a partir da técnica bibliométrica.

\section{Palavras-chave}

E-judiciário; Bibliometria; Gestão.

\section{Abstract}

A new Judiciary model is under construction and there are many topics that require reflection. It is observed that many publications have been carried out in this direction, but there is no systematic work of mapping of the situation in highly qualified journals. In this sense, the objective of this study is to survey the articles indexed in SCIELO. br base to respond to the three subject areas: management of the judiciary, Electronic Process and information security in the judiciary. The results will be organized in an explanatory diagram of sub-themes. Thus, the method of approach used was the inductive, with case study procedure and a bibliometric technique.

\section{Key words}

E-judiciary; Bibliometrics; Management. 


\section{Introdução}

O Poder Judiciário, assim como outras instituiçôes, vem buscando adaptar-se às profundas mudanças sofridas pela sociedade. Esse processo nos leva a caminho do chamado e-Judiciário, numa clara alusão ao uso intensivo das novas tecnologias.

Esse novo modelo de Poder Judiciário possui várias frentes de transformação, muitos são os temas que exigem reflexão. Entre eles a própria ideia de uma nova gestão do judiciário, a implantaçáo do Processo Eletrônico e questóes de segurança da informação. Enfim, o Judiciário eletrônico é algo que se está construindo e necessita constante reflexão sobre seus avanços e mudanças, de tal forma que um bom conteúdo de pesquisas sobre isso já se produziu no Brasil.

Nesse sentido, o objetivo deste trabalho é fazer um levantamento dos artigos indexados na base do SCIELO que respondam às três áreas acima referidas, quais sejam, gestão do judiciário, Processo Eletrônico e segurança da informação no judiciário. Para tanto optou-se por uma técnica bibliométrica, utilizando-se as palavras-chave: judiciário, justiça e CNJ. O período ao qual retornaram respostas à busca ficou entre 2011-15.

O método de abordagem utilizado foi o indutivo com procedimento de estudo de caso a partir da técnica bibliométrica.

\section{A Gestão do Judiciário}

No Poder Judiciário a gestão passou a ser uma meta importante. Sardeto (2013) faz um breve histórico disso, como segue. O Poder Judiciário de modo geral experimentou no final dos anos 90 uma verdadeira crise institucional por conta do grande volume de processos, do número insuficiente de magistrados e do aumento excessivo de demandas, que culminou com a Reforma do Poder Judiciário, levada a efeito pela Emenda Constitucional n. 45/2004, no intuito de modernizar o Judiciário a fim de torná-lo mais eficiente, mais transparente, mais próximo do cidadão. Inicia-se, assim, o caminho da chamada gestão judiciária. No Relatório de Atividades 2011 do Supremo Tribunal Federal, o então presidente da Corte, Ministro Cezar Peluso, ao tratar do tema gestão judiciária esclareceu que todas as inovaçóes processuais e administrativas surgidas no contexto da Reforma do Judiciário, quais sejam, a implantação do processo eletrônico, da repercussão geral e da súmula vinculante, associadas à absorção de tecnologia e de modernas concepçóes gerenciais, convergiram para a obtenção, já em boa medida, de certo grau de padronização, de simplificação de procedimentos, de identificação de demandas múltiplas e de interação com os demais tribunais do País, o que permitiu adicionar mais valor às atividades-fim do Poder Judiciário. Em 2012 o Relatório de Atividades divulgado foi o do Conselho Nacional de Justiça, aprovado em janeiro de 2013, o que vem reforçar a preocupação 
do Poder Judiciário com a gestão judiciária, uma vez que o CNJ é órgão de controle da atuação administrativa e financeira do Poder Judiciário, bem como do cumprimento dos deveres funcionais dos juízes, de acordo com art. 103-B, $\$ 4^{\circ}$ da CF. Além dessa funçáo de controle e fiscalização da Justiça, o Relatório destaca também a função do CNJ de balizar políticas públicas nacionais voltadas ao aperfeiçoamento do sistema de Justiça e à melhoria da prestação jurisdicional. Dentre outros instrumentos, o CNJ tem se utilizado do estabelecimento de metas para a concretização do seu programa de gestáo judiciária.

\section{A Implantação do Processo Eletrônico}

Ruschel (2014) apresenta rapidamente a evolução do processo de implantação do Processo Eletrônico no judiciário brasileiro, cujo início ocorreu na década passada. Podese citar como exemplo, a Justiça Federal da 4a Região, que congrega os Estados do Rio Grande do Sul, do Paraná e de Santa Catarina, que desenvolveu seu próprio Sistema de Processo Eletrônico. O sistema permitiu o processamento das ações judiciais por meio de autos totalmente virtuais, dispensando por completo o uso do papel, proporcionando maior agilidade, segurança e economia na prestação jurisdicional. O sistema de Processo Eletrônico dos Juizados Especiais da $4^{a}$ Região foi desenvolvido por servidores públicos da área da informática da Justiça Federal, em "softwares livres”, o qual não teve custos de licenças de software para o tribunal. A partir de fevereiro de 2010, os demais processos cíveis e os criminais da Justiça Federal de primeiro e segundo do Tribunal Regional Federal da $4^{\mathrm{a}}$. Região, também passaram a ser ajuizados exclusivamente pelo meio eletrônico. As açôes propostas até a data da implantação do Processo Eletrônico continuarão tramitando em autos físicos, podendo ser digitalizados e tramitar em meio eletrônico, a critério do TRF da 4a . Região, conforme o Art. 52 da Resolução TRF/4a n. 17, de 26 de março de 2010. O CNJ, dentre suas ações de modernização do judiciário, tem incentivado o desenvolvimento de sistemas de processo eletrônico e "exigido" a sua utilização pelos Tribunais. No conjunto de Metas Nacionais de Nivelamento do Poder Judiciário planejados em 2009 a de n. 10 trata de implantar o processo eletrônico em parcela de suas unidades judiciárias. A utilização do Processo Eletrônico está presente em todos os Tribunais brasileiros, mas em diferentes escalas, avançando para num futuro próximo eliminar por completo os autos físicos. O Sistema CNJ-Projudi foi um software de tramitação de processos judiciais mantido pelo Conselho Nacional de Justiça e teve franca expansão em todos os estados do Brasil até recente mudança de rumo. Atualmente, o Processo Judicial Eletrônico (Pje) foi um sistema desenvolvido pela Subsecretaria de Informática do TRF-5 e foi adotado pelo CNJ para se tornar a única ferramenta em todo judiciário; pelo menos esta é a pretensão, de difícil realização em face da diversidade atual de sistemas em uso e a complexidade específica de cada judiciário. 
Segundo MULLER (2014) as alteraçóes resultantes da adoção do processo judicial digital no funcionamento da Justiça são significativas e viabilizam muitas mudanças nas rotinas de trabalho para a adoção do processo judicial digital: a) Rompimento com a estruturação do processo tradicional; b) Os atos processuais são praticados diretamente no sistema pelos operadores do direito, mediante a assinatura digital, baseada em certificado digital emitido por Autoridade Certificadora credenciada; c) Interação entre todos os operadores do direito por meio do sistema; d) A juntada de documentos e expediçáo de certidóes é automatizada, eliminando a burocracia; e) Possibilidade de Consulta e Controle, em tempo real e de maneira remota, do andamento dos processos pelas partes e operadores do direito; f) Celeridade na distribuição, tramitação e julgamento de todo tipo de processo ou recurso, pois os atos processuais são realizados de forma totalmente eletrônica; g) Acesso instantâneo aos dados e autos processuais; h) Publicação de atos no Diário da Justiça Eletrônico.

\section{Segurança da Informação}

Não é de hoje a necessidade de se proteger as informaçóes dos bancos de dados do Poder Judiciário. Contudo, devido à disponibilidade de novas tecnologias e a expansão da utilização do Processo Eletrônico a preocupação em relação ao sigilo e a segurança das informaçóes aumentaram. Ruschel (2014) discute o tema afirmando que a segurança da informação é um dos aspectos mais difíceis e trabalhosos de serem operacionalizados. Para que o gerenciamento seja efetivo e não dependa de talentos humanos, faz-se necessário o desenvolvimento e implementação de uma Política de Segurança da Informação, dirigida especialmente ao Poder Judiciário e completamente integrada ao avanço do Processo Eletrônico. A Política de Segurança da Informação deve ser entendida como um conjunto de diretrizes, normas e procedimentos que devem ser seguidos e que visam conscientizar e orientar não apenas os servidores do judiciário, mas também os entes públicos (partes nos processos) e a advocacia pública e privada que operam diretamente com os sistemas de Processo Eletrônico. Sendo assim, o judiciário busca soluçóes que possam ensejam maior segurança aos sistemas. Atualmente tem-se como estratégia fundamental: a otimização da aplicação dos recursos orçamentários do Poder Judiciário, na área de informática, através da padronização das plataformas tecnológicas, da utilização de softwares livres, sempre que possível, de aquisiçóes em escala nacional; maiores investimentos em equipamentos e softwares para a segurança das redes de informática e computadores nos Tribunais; a adoção da tecnologia de certificação digital; e a criação de escritórios e comitês para a gestão da segurança da informação. Além disso, há premissas que devem ser seguidas: independência relativa a fabricantes: escolha contínua e criteriosa de todos os produtos e serviços de segurança da informação, para obter a solução que melhor se adapta às necessidades técnicas e econômicas do Processo Eletrônico; soluçóes que se integram com a 
infraestrutura existente: uma solução de segurança é um meio e não um fim, de modo que estas sejam integradas na infraestrutura existente com o mínimo tempo de interrupção dos serviços em produção; e continuidade da solução: a segurança deve abarcar muito mais do que a estrita realização de um projeto.

\section{Uma Bibliometria Temática}

A bibliometria consiste em uma técnica de medição de índices que apontem a produção e disseminação do conhecimento científico (FONSECA, 1986). Esses índices ou indicadores possibilitam a análise de um determinado campo cientifico a fim de identificar características como: o crescimento cronológico da produção científica; a produtividade de autores e instituiçóes; a colaboração entre pesquisadores e instituiçóes; o impacto das publicaçóes; a análise e avaliação de fontes difusoras de trabalhos e a dispersão da produção científica entre as diversas fontes e temáticas, de tal forma que se pode revelar a evolução e tendências dessa área (BUFREM; PRATES, 2005).

Nesse sentido, fez-se um levantamento e análise de algumas dessas características da grande temática do e-judiciário, observando em especial, três áreas específicas, quais sejam, gestão do judiciário, processo eletrônico e segurança da informação.

Para tanto, foi feito um levantamento dos artigos indexados na base do SCIELO. A escolha dessa base deveu-se a sua importância e seriedade na indexação de periódicos de qualidade. As buscas restringiram-se ao endereço scielo.org.br, a partir do qual o retorno de artigos ocorre apenas em publicaçóes brasileiras.

Para encontrar artigos que respondam ao filtro acima proposto foram utilizadas na pesquisa as palavras-chave: judiciário, justiça e CNJ. Essa busca foi feita de forma mais ampla, pois ao se utilizar termos mais específicos como e-judiciário os resultados não eram satisfatórios (poucos resultados). Por outro lado, esta busca relativamente genérica exigiu que fosse feita uma avaliação subjetiva de cada artigo, para aí sim, determinar o foco preciso no tema e-judiciário. Utilizou-se os operadores lógicos AND e OR e as buscas recuperaram também as formas em plural o que garantiu a inclusão do maior número de estudos aderentes ao tema pesquisado.

No processo de análise dos resultados da busca realizou-se a exclusão dos estudos repetidos, dos indexados sem autoria e dos trabalhos incompletos, o que resultou um total de 29 artigos aderentes ao tema.

O período de publicação dos artigos ficou entre 2011-15, não tendo sido feita nenhuma restrição de tempo.

Foi utilizado o software excel da Microsoft para apoiar na organizaçáo dos resultados, bem como gerar as figuras para melhor representar a análise dos mesmos. 
Nesse sentido, observando-se três áreas consideradas importantes (gestão do judiciário, processo eletrônico e segurança da informação) no tema principal do e-judiciário, organizou-se o material recuperado em subtemas, representados aqui por termos ou palavras-chave. Dessa forma, dos 29 artigos retornados foram identificadas 29 subtemas. Segue a lista de termos/subtemas organizados de acordo com o número de artigos alocados para cada um: comprometimento organizacional (1); competição política (1); gestão de pessoas (1); inclusão digital (1); liderança (1); boas práticas (1); controle (1); desempenho (1); gestão do conhecimento (1); performance (1); planejamento estratégico (1); produtividade (1); avaliação de portais (1); gerenciamento eletrônico de documentos (1); governança de tecnologia (1); tomadas de decisão (1); accountibility (2); judiciário e democracia (2); política judiciária (2); transparência pública (2); dimensões, indicadores (2); desenvolvimento institucional (3); eficiência, efetividade (3); metodologias (DEA, SBC) (4); gestão estratégica (5); governança judicial (5); processo judicial eletrônico (5); celeridade, tempo de espera (6); CNJ (8).

Em face do número elevado de subtemas encontrados fez-se necessário definir dimensóes que pudessem agrupar em conjuntos menores e significativos esses termos. $\mathrm{O}$ esquema que melhor pareceu responder a esse critério retirou-se da tríade clássica adotada pela gestão de organizaçóes, que bem diferencia características, mantendo uma interseção entre elas, qual seja: pessoas, tecnologias e processos (figura 1). Ou seja, as organizaçóes são compostas por pessoas que desempenham atividades por meio de processos definidos e com suporte das tecnologias da informação (GONÇALVES, 2000).

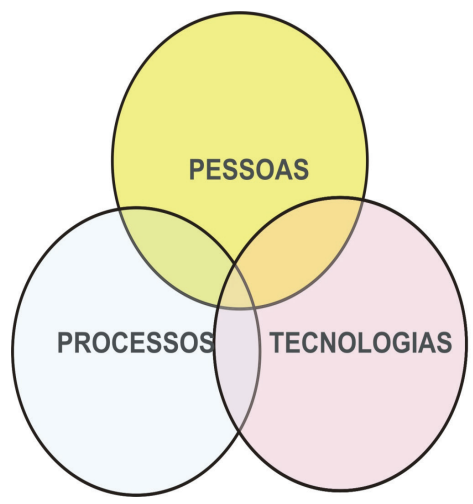

Figura 1: Tríade clássica adotada pela gestão de organizaçóes

Dessa forma, com base nesse tripé, dividiu-se os subtemas/termos nessas três dimensões, procurando-se eliminar possíveis ambiguidades de pertencimento dos mesmos. Dos 29 artigos, 5 trataram de questóes relativas à dimensão pessoas, 7 à dimensão tecnologias e 17 à dimensão processos. 


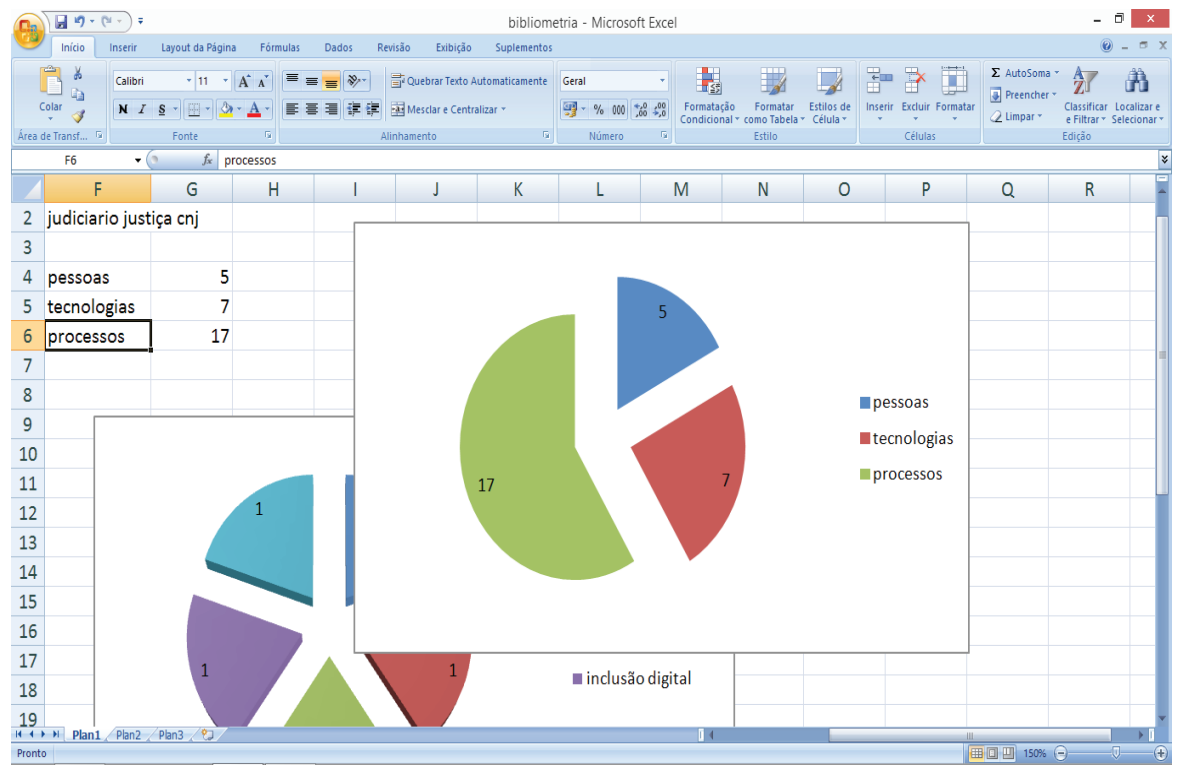

Figura 2: Número de artigos nas três dimensôes

A dimensão pessoas (figura 3) alocou os seguintes subtemas/termos: comprometimento organizacional, competição política, gestão de pessoas, inclusão digital e liderança. Observa-se que é a dimensão com o menor número de artigos (5) e para cada subtema (5) apenas 1 artigo foi alocado, demonstrando que a produção científica é pequena. Assim, é possível concluir que esta temática está subvalorizada e ao mesmo tempo pode permitir avanços com novas propostas de pesquisa.

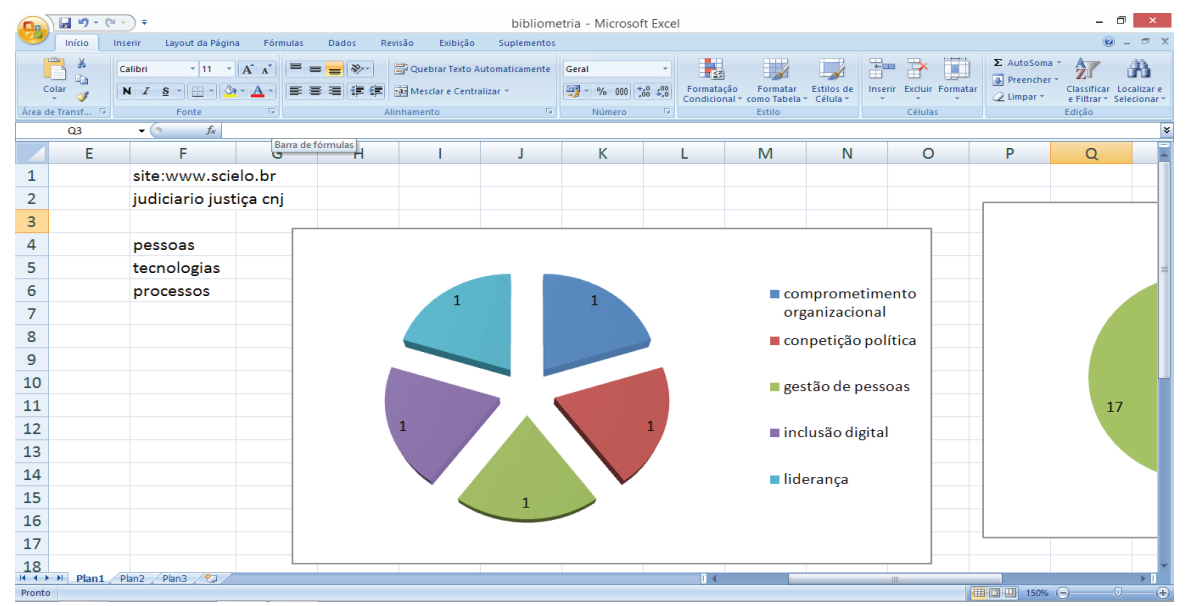

Figura 3: Número de artigos na dimensão pessoas 
A dimensão tecnologias alocou os seguintes subtemas/termos: avaliação de portais, gerenciamento eletrônico de documentos, governança de tecnologia, tomadas de decisão, dimensôes/indicadores, metodologias (DEA, SBC) e processo judicial eletrônico. Observa-se que é uma dimensão com um número mediano de artigos (7) e tendo dois subtemas com um número alto de artigos alocados. Significa dizer que é uma temática que mesmo tendo subtemas bem discutidos, possui um relativo desiquilíbrio, tendo tópicos ainda com pouca discussão científica, mas ao mesmo tempo podendo representar boas oportunidades de iniciativa de estudos.

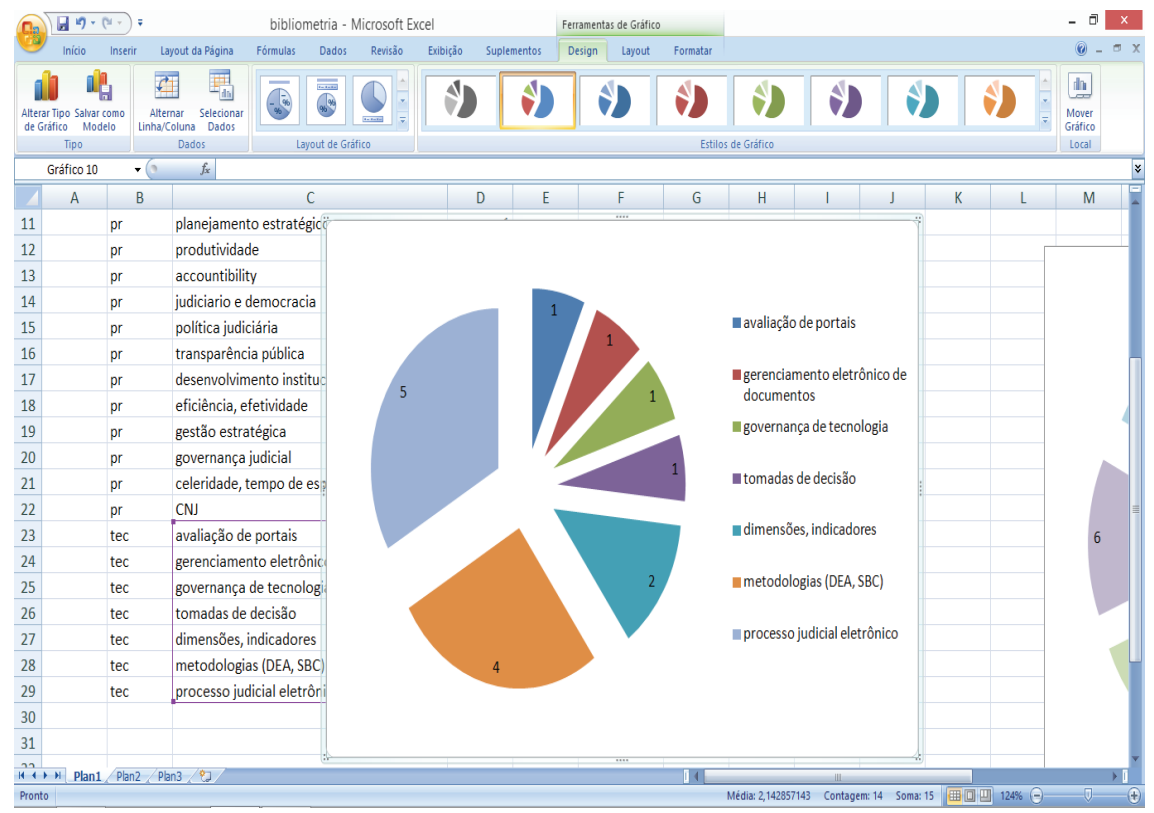

Figura 4: Número de artigos na dimensão tecnologias

A dimensão processos alocou os seguintes subtemas/termos: boas práticas, controle, desempenho, gestão do conhecimento, performance, planejamento estratégico, produtividade, accountibility, judiciário e democracia, política judiciária, transparência pública, desenvolvimento institucional, eficiência/efetividade, gestão estratégica, governança judicial, celeridade/tempo de espera, CNJ. Observa-se que é a dimensão com o maior número de artigos (17), tendo 4 subtemas com um número alto de artigos alocados, outros 6 com um número mediano e outros 7 com apenas 1 artigo alocado cada. Significa dizer que é uma dimensão bastante diversificada, numerosa e com uma boa quantidade de reflexóes sobre esses subtemas. Mesmo assim, há um terço dos subtemas com pouca discussão científica, o que mesmo nessa dimensão ainda pode haver boas oportunidades de iniciativa de estudos. 


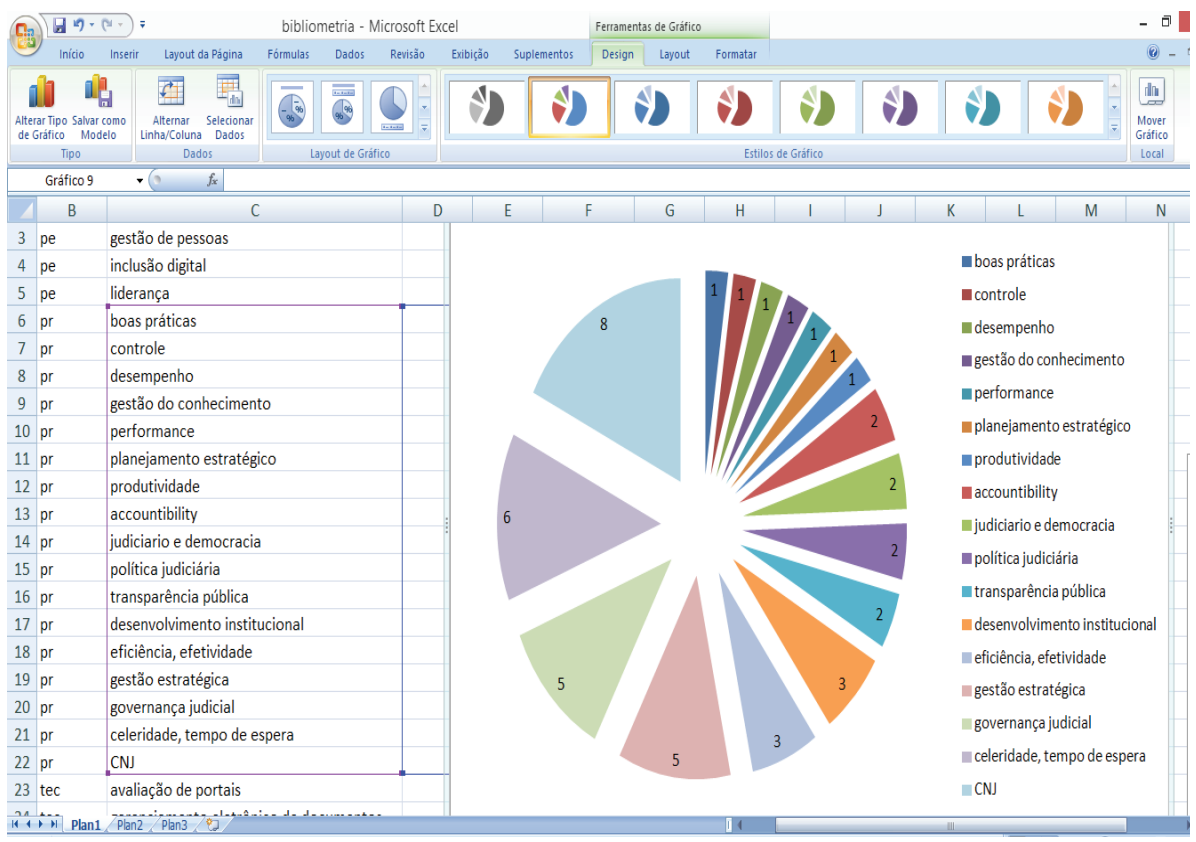

Figura 5: Número de artigos na dimensão processos

Enfim, de maneira geral, as 3 dimensôes são carentes de uma distribuição equitativa de artigos, dentro de cada uma delas e em relaçáo uma a outra, considerando-se que os subtemas aqui indicados tenham sua importância dentro do contexto proposto em face da temática do e-judiciário. Observa-se, finalmente, uma ausência importante e preocupante: nenhum artigo foi recuperado que tratasse de qualquer discussão sobre segurança da informação no judiciário. Por isso, não aparece em nenhuma das dimensóes como subtema/termo.

\section{Conclusões}

O objetivo da presente pesquisa foi realizar um mapeamento quantitativo das publicaçóes científicas sobre o tema e-judiciário, observando-se em especial as três áreas: gestão do judiciário, Processo Eletrônico e segurança da informação no judiciário. Para tanto optou-se por uma técnica bibliométrica e um esquema de organização em 3 dimensões dos subtemas encontrados a partir das buscas feitas.

Dessa forma, a partir dos resultados, é possível afirmar que no Brasil a grande temática do e-judiciário não é objeto de forte publicação em revistas de excelência.

Observando-se as 3 áreas indicadas como referência desta grande temática, ou seja, gestão do judiciário, processo eletrônico e segurança da informação no judiciário, nota-se 
que as duas primeiras são fortemente representadas no limitado número de artigos recuperados. A última, segurança da informação no judiciário, simplesmente, não aparece, o que é preocupante.

Por outro lado, levando-se em conta as dimensóes propostas, também há um desequilíbrio considerável, principalmente em relação à dimensão pessoas, muito pouco trabalhada, mesmo em face de sua importância no tripé das organizaçóes. Já a dimensão tecnologias, mesmo sendo muito falada, possui um número mediano de artigos alocados, focando muito em dois subtemas isolados. A dimensão processo já é bastante diversificada, numerosa e com uma boa quantidade de reflexóes, podendo ainda avançar nos subtemas pouco discutidos.

Enfim, espera-se que os resultados apresentados nesse artigo colaborem para a disseminação e mapeamento do tema e-judiciário, em suas múltiplas nuances e possam contribuir para o crescimento das pesquisas sobre o tema no Brasil.

\section{Referências}

BUFREM, L.; PRATES, Y. O saber científico registrado e as práticas de mensuração da informação. Ciência da Informação, Brasília, v. 34, n. 2, p. 9-25, 2005.

FONSECA, E. N. Bibliometria: teoria e prática. São Paulo: Cultrix, Ed. da USP, 1986.

GONÇALVES, José Ernesto Lima. As empresas são grandes coleções de processo. RAE Revista de Administraçáo de Empresas, v. 40, n. 1, p. 6-19, jan/mar 2000.

MULLER, Leonardo de Oliveira et al. Avaliação da expansão do processo judicial digital no Tribunal de Justiça de São Paulo sob a ótica da gestão de projetos: um estudo do projeto PUMA. In: XLIII Jornadas Argentinas de Informática e Investigación Operativa (43JAIIO)-XIV Simposio Argentino de Informática y Derecho (SID) (Buenos Aires, 2014). 2014.

RUSCHEL, Airton, LAZZARI, João, ROVER, Aires José. O processo judicial eletrônico no Brasil: uma visão geral. In: Marcus V F Coelho; Luiz Allemand (org). Processo judicial eletrônico. Editora OAB Brasília, pags 13-28, 2014.

SARDETO, Patricia Eliane da Rosa; ROVER, Aires José. A cooperação judiciária no Brasil em face do e-Judiciário. Revista Democracia Digital e Governo Eletrônico, n. $8,2013$. 